\title{
Beyond Isolation
}

\section{Benefits and Challenges as perceived by students throughout online collaboration during the

\author{
COVID-19 pandemic
}

\author{
Fei Xue, FX, and Xue \\ University of California, Davis, USA \\ feixue@ucdavis.edu \\ James Housefield, JH, and Housefield \\ University of California, Davis, USA \\ jehousefield@ucdavis.edu
}

\author{
Margaret Merrill, MM, and Merrill \\ University of California, Davis, USA \\ mmerrill@ucdavis.edu \\ Timothy Mcneil, TM, and Timothy \\ University of California, Davis, USA \\ tjmcneil@ucdavis.edu
}

\begin{abstract}
Collaboration provides opportunities for students to absorb different perspectives of knowledge [1,2] and generate more creative ideas $[3,4]$. In the design discipline, collaboration is essential for designers to identify problems, needs, and opportunities, and to promote an iterative design process [5, 6]. The COVID-19 pandemic introduced challenges for both instructors and students in 2020 as these collaborations could not happen in person. We surveyed the students in a large design fundamentals class about their online collaborative experience throughout the three phases of their individual design projects. We share findings about the benefits and challenges students perceived during this collaboration. This study contributes to our understanding of the power of collaboration, especially in an online environment. Our findings can empower instructors and researchers to build more engaging online learning experiences by including opportunities for student collaboration.
\end{abstract}

\section{CCS CONCEPTS}

- Human-centered computing; • Collaborative and social computing; - Empirical studies in collaborative and social computing;

\section{KEYWORDS}

Teaching and learning, Online student collaboration, Survey method, Teaching design development

\section{ACM Reference Format:}

Fei Xue, FX, and Xue, Margaret Merrill, MM, and Merrill, James Housefield, $\mathrm{JH}$, and Housefield, and Timothy Mcneil, TM, and Timothy. 2021. Beyond Isolation: Benefits and Challenges as perceived by students throughout online collaboration during the COVID-19 pandemic. In Companion Publication of the 2021 Conference on Computer Supported Cooperative Work and Social Computing (CSCW'21 Companion), October 23-27, 2021, Virtual Event, USA. ACM, New York, NY, USA, 4 pages. https://doi.org/10.1145/3462204.3481744

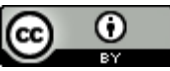

This work is licensed under a Creative Commons Attribution International 4.0 License.

CSCW'21 Companion, October 23-27, 2021, Virtual Event, USA

(c) 2021 Copyright held by the owner/author(s).

ACM ISBN 978-1-4503-8479-7/21/10.

https://doi.org/10.1145/3462204.3481744
}

\section{INTRODUCTION}

Although the value of creative collaboration $[1,2]$ is well established, how online creative collaboration happens is still relatively unexplored. The COVID-19 pandemic introduced challenges in this area for both instructors and students. For many, this was their first time engaging in various teaching and learning practices with technology [7] with limited time to familiarize themselves with relevant practices and tools. Under these circumstances, it was difficult for these instructors to know how to make effective online collaboration happen. Understanding students' perceptions about their online collaboration can provide insights for instructors on planning better collaborations.

Previous studies have explored issues of collaborative design, including communication patterns [8], pedagogical methodology [9], and design outcomes [6], yet there is limited research focusing on students' perspectives throughout the design process, especially within online learning environments. Within the unique learning and designing processes during the pandemic, how did students perceive the benefits and challenges of collaborative activities? How could we better build online creative collaboration opportunities? Exploring these questions can lead to meaningful pedagogical insights for the CSCW community. Designing through group collaboration is also a learning process, because students generate ideas, discuss, critique, prototype, communicate with each other, and implement the final prototypes throughout an iterative design process $[6,10]$. While previous research emphasizes the significance of collaboration in design education, such as brainstorming leading to effective design outcomes [11] and collaborative context fostering participatory culture [12], several challenges regarding online collaboration have been raised. These challenges include fewer opportunities for the non-verbal cues that happen in face-to-face communication $[8,13]$, difficulty in achieving a shared understanding of the task [13,14], and being highly dependent on technology [15]. In addition, online collaboration is not always as straightforward as traditional in-person collaboration. Since telecommunication limits opportunities for emotional cues and face-to-face interactions, it might be more challenging for students to build an affinity space online than in a physical collaborative context $[13,16]$. Therefore, this study took advantage of the unique opportunity presented by the COVID pandemic to investigate students' online collaborative experiences in a remote design fundamentals class. We addressed 
the following research question: what are students' perceived benefits and challenges about their online collaboration throughout an independent design process?

This work makes the following contributions: (1) expanding the understanding of students' perceptions in online design collaboration, (2) empowering instructors to build more engaging online learning experiences by including opportunities for student collaboration, and (3) identifying challenges that students might face in an online collaboration so that instructors can plan to minimize or mitigate those challenges.

\section{METHODS}

We conducted a thematic analysis through a process of inductive coding on all students' survey responses. Emergent codes were derived from multiple coding passes and mainly reflected students' perceived benefits and challenges throughout three phases of the design process (Table 1). All study procedures were approved by the university's Institutional Review Board.

\section{FINDINGS}

Five themes emerged from the data, with students identifying benefits and challenges related to each theme: cognitive, affective, instructional, communicational, and technology-based benefits and challenges. Table 1 contains descriptions, examples, and frequency counts of each of the five themes. The frequency counts indicate the number of relevant comments found in the 701 total survey responses.

\subsection{Cognitive benefits and challenges}

Cognitive benefits were revealed in student comments about cognitive processes such as thinking, remembering, and problem-solving. Many students mentioned "receiving feedback" and "seeing other's work" as cognitive benefits from the collaboration. This aligns with the nature of design - seeing other's work can be viewed as a visual learning process since it helps designers better understand how others approach the problem, develop the solution, and communicate with the audience via visuals. In contrast, some students mentioned that their design thinking was thwarted by "seeing other's work" and understanding that some students had a "different mindset."

\subsection{Affective benefits and challenges}

Affective benefits and challenges came up in student comments about feelings or emotions. The most frequent affective benefits students mentioned included feeling "encouragement", "confidence", "support", and "less isolating". In contrast, a few students expressed that they felt "stressed to communicate with others online" and that it was "hard to get a sense of belonging throughout online collaboration". Given that this online collaboration happened during the pandemic, these affective perceptions seem to indicate students' desire of cultivating online belonging and supportive communities throughout the collaboration, but such emotional support is still highly dependent on student's comfort level of the online environment.

\subsection{Instructional benefits and challenges}

Instructional benefits and challenges were found in student comments about instructional considerations such as being on track or following the class. Some students expressed that online collaboration brought instructional benefits such as "keep[ing] me on the right track" and "clarify[ing] the assignment", while other responses indicated that the "collaboration made the instruction more confusing" and that there was "no[t] enough time for in-depth collaboration before deadlines". These findings indicated the importance of providing instructional guidelines [23] before actual collaboration.

\subsection{Communicational benefits and challenges}

Communicational benefits and challenges were found in student comments about the communicational aspects of collaboration such as chatting, sharing and receiving feedback, discussion, etc. The most frequent perceived communicational benefits from students' responses included "sharing and hearing feedback" and "improving my interpersonal skills". However, some students also mentioned that they perceived communication challenges throughout the collaboration such as "low engagement" and "superficial networking". Some student comments indicate that the low engagement is at least partially related to the time difference among group members due to remote instruction, which made it hard for students to schedule synchronous meetings for collaboration. Moreover, "lack of verbal cues [13]" was mentioned several times in students' responses, which could lead misunderstanding among groups.

\subsection{Technology-based benefits and challenges}

Several students perceived technology-based benefits created by the online environment such as "efficiency", "various helpful tools", and "convenience". At the same time, some students worried about their online collaboration due to "the nature of the virtual environment" and the "lack [of] in-person cues when online". In many cases, student comments about technology-based benefits and challenges also included elements that related to other themes. For example, some students mentioned the communicational benefits of using various technological tools. In contrast, some students who faced communicational or affective challenges tended to blame the online environment for these challenges.

\section{DISCUSSION AND CONCLUSION}

The above findings provide insights into students' perceived benefits and challenges regarding their online collaboration throughout a fundamental design class during the 2020 pandemic. These preliminary results confirm findings from previous literature (see Table 1) and provide new insights. For example, student responses indicated more benefits (mainly in the cognitive, communicational, and affective themes) than challenges in their online collaboration. This finding supports the potential of online collaboration to promote student learning and engagement [7]. Moreover, the challenges of online collaboration most frequently mentioned by students are communicational challenges. Our findings indicate that communicational challenges often overlap with other challenges, such as instructional or technology-based challenges. These specific challenges echo findings in recent studies $[22,23]$ and indicate two areas 
Table 1: Perceived benefits and challenges in students' online collaboration

\begin{tabular}{ll}
\hline Benefit(Frequency Counts) & Description \\
\hline $\begin{array}{l}\text { Cognitive benefits } \\
(481)\end{array}$ & $\begin{array}{l}\text { Benefits perceived from the } \\
\text { cognitive process such as } \\
\text { thinking, remembering, and } \\
\text { problem-solving, etc. }\end{array}$
\end{tabular}

Affective Benefits

(41)

Benefits perceived from feelings or emotions.

Instructional Benefits

Communicational Benefits

Technology-based benefits

\section{Challenge \\ (Frequency Counts) \\ Cognitive Challenges

\section{Affective Challenges \\ (34) \\ Instructional Challenges}

Communicational challenges (157)

Technology-based challenges (100)
Benefits perceived from the instructional consideration such as on track or following class.

Benefits perceived from communicational aspects such as chat, sharing and receiving feedback, discussion, etc. Benefits perceived from certain types of technology or online learning environments.

Challenges perceived from the cognitive process such as thinking, remembering, and problem-solving, etc.

Challenges perceived from the feelings or emotions.

Challenges perceived from the instructional consideration such as on track, submitting assignments, and following curriculum.

Challenges perceived from communicational aspects such as chat, sharing and receiving feedback, discussion, etc. Challenges perceived from certain types of technology or online learning environment.

Example

"Being able to see other people's work was the most helpful part of collaboration. It gave me inspiration as to how I should lay out my project. Giving feedback to others also helped me to understand what I could change in my work too."

"I think the amount of support and understanding that my group mates have has immensely made the design process go more smoothly! Both the critical and positive feedback have been more motivating for me!"

"I liked that I was able to get feedback and see if I was on the right track."

"I think the ability to easily get in contact [with] my peers and having an easy, and almost instant, access to their work to peer review has been beneficial."

"Zoom has made meetings very easy and allowed us to meet frequently."

"We have each struggled with our own ideas and through our own process so it has been difficult to help each other."

"The stress of having to communicate with people you have never met."

"There is not enough time to change my project to incorporate feedback before it is due."

"We ran into a problem where people weren't replying to emails and a question I had that led to miscommunication."

"Time zone difference. We have a group member that is 15 hours ahead of us and it was kind of hard to communicate with that group member."
Connections to

previous research

"Promoting critical thinking and problem solving" $[8,17,18]$

"Supporting social and emotional well-being"

$[8,17,18]$

"Increasing efficiency" $[8,17,18]$

"As a vital communication skill" [19]

"Technology to support social interaction online" [20]

"Difficulty in achieving a shared understanding of the task" [14]

"Lack emotional cures" [13].

"Deadlines could have a negative effect on the collaboration process" [21].

"Lacking verbal communication skills" [13]

"Nature of the virtual environment" [13] for future research - the value of instructional design guidelines and the importance of establishing online presence.

Our future analysis will focus on the changes in these perceived benefits and challenges as the students transitioned from one design phase to the next. Understanding how students' perceptions of their online collaboration shift throughout each phase of the design process can help us better understand how students react to each design goal throughout the collaborative learning process. Future research could explore the following questions: how could we achieve these same collaboration benefits in in-person classrooms and instruction? How could we avoid the potential challenges identified in this 
paper if we incorporate collaboration into curriculum design? All of these questions are worth exploring for $\mathrm{CSCW}$ research and the broad educational area. More importantly, the lessons learned from online collaboration during the pandemic will continue to inform us further beyond the pandemic and can also be explored in other disciplines.

\section{REFERENCES}

[1] Wenzhi Chen and Manlai You. 2010. Student response to an Internet-mediated industrial design studio course. International Journal of Technology and Design Education 20, 2: 151-174. https://doi.org/10.1007/s10798-008-9068-2

[2] Jan-Willem Strijbos. 2011. Assessment of (Computer-Supported) Collaborative Learning. IEEE Transactions on Learning Technologies 4, 1: 59-73. https://doi. org/10.1109/TLT.2010.37

[3] G. Makransky and P. Wismer. 2019. A gender matching effect in learning with pedagogical agents in an immersive virtual reality science simulation. Journal of Computer. Retrieved from https://onlinelibrary.wiley.com/doi/abs/10.1111/jcal 12335

[4] Chien Wen (tina) Yuan, Yu-Hsuan Liu, Hao-Chuan Wang, and Yuan-Chi Tseng. 2019. Gender Effects on Collaborative Online Brainstorming Teamwork. In Extended Abstracts of the 2019 CHI Conference on Human Factors in Computing Systems (CHI EA '19), 1-6. https://doi.org/10.1145/3290607.3312989

[5] Heidy Maldonado, Brian Lee, and Scott Klemmer. 2006. Technology for design education: a case study. In CHI '06 Extended Abstracts on Human Factors in Computing Systems (CHI EA '06), 1067-1072. https://doi.org/10.1145/1125451. 1125654

[6] Jeehyun Lee, Jiwon Ahn, Jieun Kim, and Jeong-min Kho. 2019. Co-design education based on the changing designer's role and changing creativity. International journal of art \& design education 38, 2: 430-444. https://doi.org/10.1111/jade. 12204

[7] Meeli Rannastu-Avalos and Leo Aleksander Siiman. 2020. Challenges for Distance Learning and Online Collaboration in the Time of COVID-19: Interviews with Science Teachers. In Collaboration Technologies and Social Computing, 128-142. https://doi.org/10.1007/978-3-030-58157-2 9

[8] Neal Dreamson. 2017. Online collaboration in design education: An experiment in real-time manipulation of prototypes and communication. International journal of art \& design education 36, 2: 188-199. https://doi.org/10.1111/jade.12079

[9] Carol Rogers-Shaw, Davin J. Carr-Chellman, and Jinhee Choi. 2018. Universal Design for Learning: Guidelines for Accessible Online Instruction. Adult Learning 29, 1: 20-31. https://doi.org/10.1177/1045159517735530

[10] Huyen N. Nguyen, Vinh T. Nguyen, and Tommy Dang. 2020. Interface design for HCI classroom: From learners' perspective. In Advances in Visual Computing. Springer International Publishing, Cham, 545-557. https://doi.org/10.1007/978-3030-64559-5_43
[11] Rick Bennett Ouita Broadfoot. 2003. Design Studios: Online? Comparing traditional face-to-face Design Studio education with modern internet-based design studios. Retrieved August 27, 2020 from http://citeseerx.ist.psu.edu/viewdoc/ summary?doi=10.1.1.124.3548

[12] Thomas Kvan. 2001. The pedagogy of virtual design studios. Automation in Construction 10, 3: 345-353. https://doi.org/10.1016/S0926-5805(00)00051-0

[13] Björn Stockleben, Martyn Thayne, Seija Jäminki, Ilkka Haukijärvi, Nicholas Blessing Mavengere, Muhammet Demirbilek, and Mikko Ruohonen. 2017. Towards a framework for creative online collaboration: A research on challenges and context. Education and Information Technologies 22, 2: 575-597. https: //doi.org/10.1007/s10639-016-9483-z

[14] Allyson F. Hadwin, Aishah Bakhtiar, and Mariel Miller. 2018. Challenges in online collaboration: effects of scripting shared task perceptions. International journal of computer-supported collaborative learning 13, 3: 301-329. https://doi.org/10. 1007/s11412-018-9279-9

[15] Mary Thorpe. 2002. Rethinking Learner Support: The challenge of collaborative online learning. Open Learning: The Journal of Open, Distance and e-Learning 17, 2: 105-119. https://doi.org/10.1080/02680510220146887a

[16] J. Preece and D. Maloney-Krichmar. 2005. Online communities: Design, theory, and practice. Journal of computer-mediated communication: JCMC. Retrieved from https://academic.oup.com/jcmc/article-abstract/10/4/JCMC10410/4614449

[17] Nancy Yen-Wen Cheng. 2003. Approaches to design collaboration research. Automation in Construction 12, 6: 715-723. https://doi.org/10.1016/S0926-5805(03) 00059-1

[18] Branko Kolarevic, Gerhard Schmitt, Urs Hirschberg, David Kurmann, and Brian Johnson. 2000. An experiment in design collaboration. Automation in Construction 9, 1: 73-81. https://doi.org/10.1016/S0926-5805(99)00050-3

[19] Chin-Wen Liao, Ching-Huei Chen, and Sie-Jhih Shih. 2019. The interactivity of video and collaboration for learning achievement, intrinsic motivation, cognitive load, and behavior patterns in a digital game-based learning environment. Computers \& education 133: 43-55. https://doi.org/10.1016/j.compedu.2019.01.013

[20] Karel Kreijns, Paul A. Kirschner, and Wim Jochems. 2002. The sociability of computer-supported collaborative learning environments. Educational technology \& society 5, 1: 8-22. Retrieved from https://www.jstor.org/stable/pdf/ jeductechsoci.5.1.8.pdf

[21] Anil Pathak and Charatdao Intratat. 2012. Use of semi-structured interviews to investigate teacher perceptions of student collaboration. Malaysian Journal of ELT Research 8, 1:1.

[22] Zhilong Chen, Hancheng Cao, Yuting Deng, Xuan Gao, Jinghua Piao, Fengli Xu, Yu Zhang, and Yong Li. 2021. Learning from Home: A Mixed-Methods Analysis of Live Streaming Based Remote Education Experience in Chinese Colleges during the COVID-19 Pandemic. In Proceedings of the 2021 CHI Conference on Human Factors in Computing Systems. Association for Computing Machinery, New York, NY, USA, 1-16. https://doi.org/10.1145/3411764.3445428

[23] Xinyue Chen, Si Chen, Xu Wang, and Yun Huang. 2021. "I was afraid, but now I enjoy being a streamer!": Understanding the Challenges and Prospects of Using Live Streaming for Online Education. Proc. ACM Hum.-Comput. Interact. 4, CSCW3: 1-32. https://doi.org/10.1145/3432936 